\title{
Prevalence of inappropriate tuberculosis treatment regimens: a systematic review
}

\author{
M.W. Langendam*, M.J. van der Werf*, ${ }^{\#,}$ E. Huitric ${ }^{+}$and D. Manissero ${ }^{+}$
}

ABSTRACT: A potential threat to the success of new tuberculosis (TB) drugs is the development of resistance. Using drugs in appropriate regimens, such as those recommended in the World Health Organization (WHO) treatment guidelines, prevents the development of resistance. We performed a systematic review to assess the prevalence of inappropriate prescription of TB drugs for the treatment of TB.

MEDLINE, EMBASE and other databases were searched for relevant articles in January 2011. Observational studies published from 2000 that included TB patients receiving treatment were selected. A treatment regimen was considered inappropriate if the regimen was not a WHO recommended regimen.

37 studies were included. Inappropriate treatment regimens were prescribed in $67 \%$ of studies. The percentage of patients receiving inappropriate regimens varied between $0.4 \%$ and $100 \%$. In 19 studies the quality of treatment regimen reporting was low.

Despite the fact that assessment of inappropriate treatment was hampered by low quality of reporting, our data indicate a reasonable amount of inappropriate prescription of TB treatment regimens. Thus, there is a risk that new drugs will be used in inappropriate treatment regimens, even with WHO guidelines in place, introducing the risk of resistance development. This article highlights the need to improve implementation of the WHO treatment of TB guidelines.

\section{KEYWORDS: Inappropriate, regimen, treatment, tuberculosis}

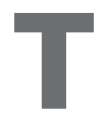
he currently used tuberculosis (TB) drugs date back more than 50 yrs. Soon after their introduction the emergence of drug resistance was observed [1]. This led to the use of a double-drug combination to prevent the emergence of drug resistance, and later to triple-drug combinations. Four-drug short-course regimens were first tested in 1972 and showed positive results [2]. A four-drug short-course regimen is currently recommended by the World Health Organization (WHO) [3].

Recently, 10 compounds have progressed to the clinical development stage for the treatment of TB [4]. These new compounds, if properly managed, have the potential to become part of a future regimen that could greatly impact on the global TB control effort. A potential threat to the success of the new compounds is the development of resistance caused by inappropriate use of these drugs [5]. For these new drugs to remain effective it is essential that they are used in regimens that prevent the development of resistance to the drugs. The WHO has developed guidelines on appropriate (standardised) TB treatment regimens that will cure patients and prevent the development of resistance. The first guidelines were published in 1993 [6], and updates followed in 1997 [7], 2003 [8] and 2009 [3].

Implementation of global TB treatment guidelines requires the uptake of the recommendations in national TB treatment guidelines and the use of national treatment guidelines by all health workers. Initially, $83(48 \%)$ out of 174 countries reporting to the $\mathrm{WHO}$ did not accept the WHOTB control strategy [9]. 10 yrs later, most countries were implementing the DOTS (Directly Observed Treatment Short Course) strategy, including fourdrug short-course regimens. Although countries have implemented the DOTS strategy, individual healthcare workers might not be aware of the strategy or might not be willing to implement the
AFFILIATIONS

*Dutch Cochrane Centre, Academic Medical Center,

'Center for Infection and Immunity Amsterdam (CINIMA), Academic Medical Center, University of Amsterdam, Amsterdam, and ${ }^{\#}$ KNCV Tuberculosis Foundation, The Hague, The Netherlands.

+European Centre for Disease Prevention and Control (ECDC), Stockholm, Sweden.

CORRESPONDENCE M.J. van der Werf KNCV Tuberculosis Foundation P.0. Box 146 2501 CC The Hague The Netherlands E-mail: vanderwerfm@kncvtbc.nl

Received: July 222011 Accepted after revision: Sept 262011

First published online: Oct 172011

This article was modified in April 2016 to correct errors in the licence information. 
recommended regimens. Studies among healthcare workers show that not all healthcare workers have been exposed to the national TB treatment guidelines and many are not prescribing recommended regimens [10-12].

In intermediate-to-low TB incidence settings, a further challenge is that healthcare workers, due to the few cases of TB presenting, might not be aware of the global guidelines on TB treatment and, thus, do not follow these. The European Union (EU) is a heterogeneous setting, with countries and settings ranging from low- to high-TB incidence [13]. The challenge in low-incidence settings is to maintain the knowledge of TB and, thus, awareness of treatment regimens and guidelines.

To assess the future risk of new compounds being used in inappropriate TB regimens, we conducted a systematic review to assess the prevalence of inappropriate TB drug prescriptions (type, dose, frequency of dosing and combination) for the treatment of TB. Appropriate treatment was defined according to the WHO guidelines.

\section{METHODS}

\section{Search strategy}

To identify relevant studies we conducted a literature search in the bibliographic databases MEDLINE and EMBASE in January 2011. We searched for guidelines in the National Guideline Clearinghouse, the National Institute of Health and Clinical Excellence (NICE) and the Scottish Intercollegiate Guidelines Network (SIGN) databases. Abstracts of conference proceedings were searched in BIOSIS. Reviews and guidelines were searched for in the TRIP database. Keywords used in the search were determined in collaboration with the clinical librarian of the Dutch Cochrane Centre (Amsterdam, the Netherlands) and included "Tuberculosis" OR "TB" OR "Mycobacterium" AND, for TB treatment, "Prescriptions" OR "Treatment regimen" OR "Combination treatment" OR "Treatment strategy/-ies" OR "Drug supply" OR "Standard treatment/standard regimen" OR "Inappropriate use, appropriate use, rational use, irrational use, misuse". The search was limited to publication years 2000-2010 as we were interested in recent prescription behaviour. We excluded case reports. The search strategy was supplemented by hand searching reference lists of identified articles and relevant review articles.

\section{Selection of studies}

We included observational studies investigating the prescription of TB treatment regimens in a TB patient population; these can include cross-sectional studies and cohort studies, both prospective and retrospective. Only studies in which treatment regimen was measured as an outcome were included. Therefore, we excluded studies in which prescription of a treatment regimen was only described in the methods section. Furthermore, we excluded studies that provided information about the prescribed drugs but not about the prescribed treatment regimens, and studies that did not report the treatment regimens in sufficient detail to make a judgment on the appropriateness of the regimen. This also included studies with multidrug-resistant TB patients that reported providing individualised treatment and did report the individual drug resistance patterns.

We searched publications from the year 2000 onwards. Papers with data collection starting before 1995 were excluded because the first WHO treatment guidelines were published in 1993. Assuming a 2-yr implementation period, these guidelines would only be expected to be followed from 1995 onwards. There was no language restriction.

Studies identified by the search strategy were reviewed for eligibility based on title and abstract by one investigator (M.J. van der Werf). Full manuscripts of the records kept based on title/abstract were assessed by one investigator (M.J. van der Werf). For both steps a 10\% random sample was assessed by a second investigator (M.W. Langendam) and compared with the assessment of the first reviewer. Inconsistencies in assessment were discussed and disagreements resolved by consensus. A complete double selection was planned if the $10 \%$ random sample revealed relevant inconsistencies.

\section{Data extraction}

One reviewer (M.W. Langendam) extracted all relevant data items from the included studies using a data extraction form. A second reviewer (M.J. van der Werf) independently extracted the main results of the included studies and checked the other extracted results for a subsample of the articles. Inconsistencies were discussed to obtain consensus.

\section{Data analysis and synthesis of results}

The results were summarised qualitatively. For studies that described treatment regimens without indicating whether they were appropriate according to the $\mathrm{WHO}$ guidelines, the regimen was assessed and assigned to the appropriate or inappropriate category using the WHO guidelines as a reference. Table 1 presents the applicable WHO guidelines for different periods of data collection in the individual studies. In the first and third editions of the WHO-TB treatment guidelines (1993 and 2003, respectively) there were specific treatment guidelines for children. In the second edition in 1997, there were no specific guidelines for children. We also noted if the authors of the manuscripts considered the regimens to be appropriate or inappropriate. If the data allowed, we assessed the adequacy of dosing frequency, dosage and duration of TB treatment. We aimed to assess the prevalence of inappropriate TB regimen prescription for different patient populations and different geographical areas.

The quality of reporting of study characteristics and treatment regimens was assessed using a quality checklist developed for this review based on the STROBE statement (www.strobestatement.org/index.php?id=strobe-home) (table 2).

\section{RESULTS}

\section{Study selection}

The search in MEDLINE and EMBASE resulted in 1,896 unique records. A total of 292 papers were considered potentially

\begin{tabular}{lcc} 
TABLE 1 & $\begin{array}{l}\text { World Health Organization (WHO) guidelines for } \\
\text { periods of data collection }\end{array}$ \\
[Ref.] \\
\hline Period of data collection & WHO guidelines & \\
\hline \multirow{2}{*}{$\mathbf{1 9 9 5 - 1 9 9 9}$} & First edition: 1993 & {$[6]$} \\
$\mathbf{1 9 9 9 - 2 0 0 4}$ & Second edition: 1997 & {$[7]$} \\
$\mathbf{2 0 0 5 - 2 0 1 0}$ & Third edition: 2003 & {$[8]$} \\
\hline
\end{tabular}




\begin{tabular}{|c|c|}
\hline Quality level & Assessment \\
\hline \multicolumn{2}{|l|}{ Setting and population } \\
\hline High quality $(* \star \star)$ & $\begin{array}{l}\text { Adequate description of } \\
\text { Population demographics: at least age and sex } \\
\text { Population TB: new/re-treatment, type of TB and smear positive/negative } \\
\text { Setting: where did the patients come from, e.g. private or public hospital, evaluation of TB control programme } \\
\text { Time period of data collection } \\
\text { Sample size } \\
\text { TB diagnosis }\end{array}$ \\
\hline Moderate quality $\left({ }^{* *}\right)$ & Adequate description of population, setting, time period of data collection and sample size, but no information on TB diagnosis \\
\hline Low quality $\left({ }^{\star}\right)$ & No information on population, setting, time period of data collection and sample size \\
\hline \multicolumn{2}{|l|}{ TB treatment regimens } \\
\hline Low quality $\left({ }^{\star}\right)$ & Treatment regimens are not specified in sufficient detail, but authors make a statement \\
\hline
\end{tabular}

TB: tuberculosis; PTB: pulmonary TB; EPTB: extra-pulmonary TB.

relevant based on title/abstract assessment (fig. 1). After fulltext assessment, 37 papers fulfilled the inclusion criteria. BIOSIS did not provide any additional records. Checking the reference lists of the included papers revealed no additional

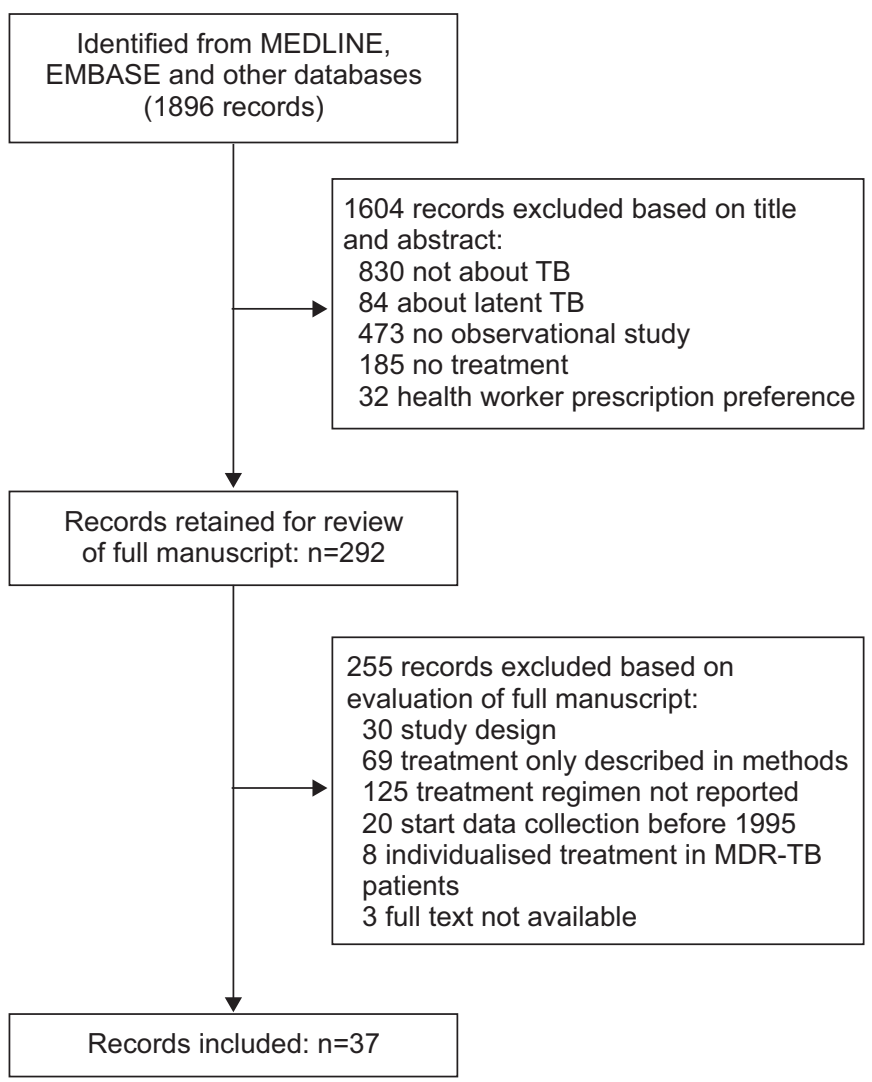

FIGURE 1. Summary of literature search and study selection. TB: tuberculosis; MDR: multidrug resistant. papers that fulfilled the inclusion criteria. The National Guideline Clearinghouse, NICE, SIGN and TRIP databases did not provide aggregated evidence on the prevalence of inappropriate use of TB regimens.

\section{Description of the included studies}

37 papers were included. Of these, 26 studies investigated treatment prescription in the general population (including three studies in children) and 11 studies were in special groups (four in extra-pulmonary TB, one in patients with isoniazidresistant $\mathrm{TB}$ and six in special patient groups).

The 37 papers were from 22 countries, and one study was from multiple countries (this study is presented in both tables 3 and $4)$. Almost all continents were represented: Africa $(n=6)$, South America $(n=2)$, Europe $(n=9)$ and Asia $(n=20)$.

The included studies did not provide sufficient information to assess adequacy of dosing frequency, dose and duration of TB treatment.

\section{General population including children}

Of the 26 studies performed in the general population, 13 $(50 \%)$ were performed in a hospital setting, 12 (46\%) were based on TB registers and one study was performed in hospitals, a prison and welfare centres (tables 3-5). The sample sizes ranged between 32 and 24,760 TB patients.

14 studies had low-quality treatment regimen reporting and 10 of these also had low-quality reporting of the study and population characteristics. For the treatment regimens, this means that the regimens were not specified or that the described regimens were applied to an undefined mix of patients (new and re-treatment cases, pulmonary TB and extra-pulmonary TB cases, and/or smear-negative and -positive cases), in which case it was not possible to categorise the treatment as appropriate or inappropriate. According to the author statements in these 14 studies, in two studies, all patients received appropriate 


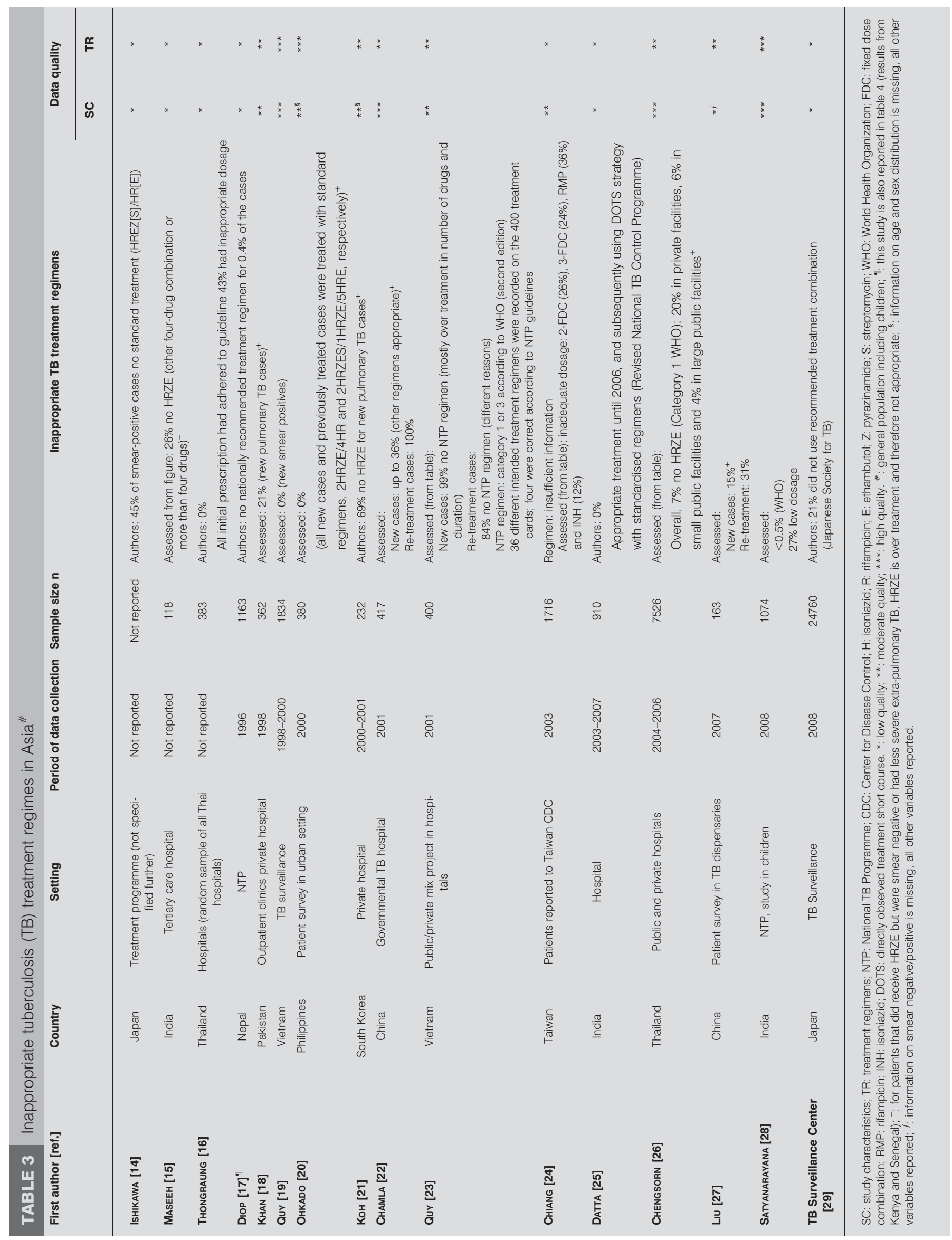




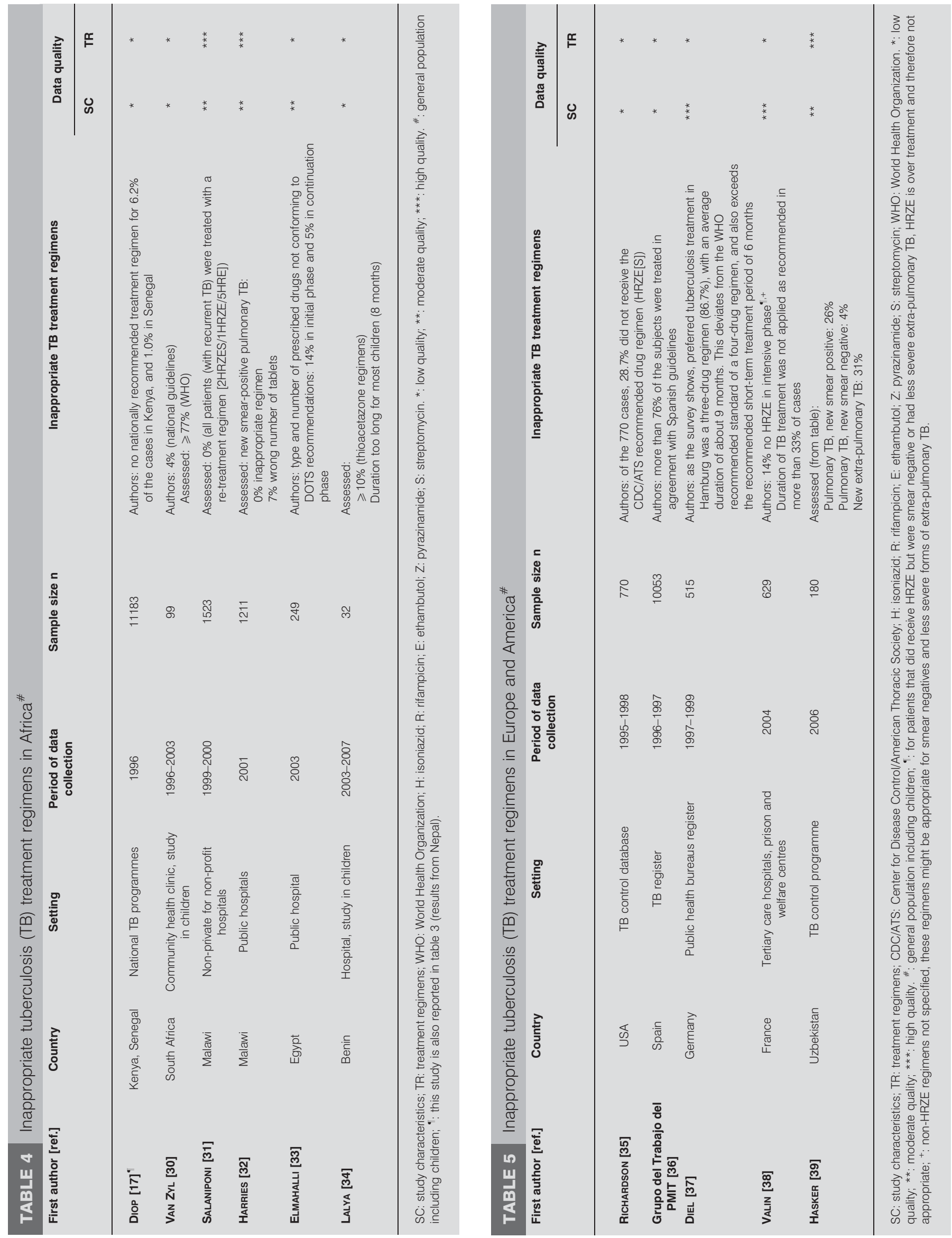


regimens [16, 25]. In eight studies, inappropriate regimens had been prescribed according to the authors; the percentage of patients on inappropriate regimens ranged from $0.4 \%$ to $45 \%$ [14, 17, 29, 30, 35-38]. For two studies we determined the prevalence of inappropriate treatment; this was $26 \%$ in the study from India and $\geqslant 10 \%$ in the study with children in Benin $[15,34]$. Two studies did not provide information on treatment regimens but reported on inadequate numbers of tablets and/or inadequate dosage [24, 33].

Six studies provided moderate quality information on the observed treatment regimens [18, 21-23, 26, 27]. In all six studies, the prevalence of inappropriate treatment regimens could be calculated from the different treatment regimens or derived from a table in the paper, under the assumption that all cases were smear-positive cases (this could not be derived from the papers). For smear-negative cases, a non-isoniazid, rifampicin, pyrazinamide, ethambutol (HRZE) regimen might be appropriate, in which case the prevalence of inappropriate treatment would be overestimated in our calculations [8]. The percentage of prescription of inappropriate TB treatment regimens ranged between $7 \%$ and $100 \%$.

For six studies, high-quality information on the observed treatment regimens was available [19, 20, 28, 31, 32, 39]. In one study, among new TB cases, inappropriate regimens were prescribed to $26 \%$ of smear-positive pulmonary TB patients, $4 \%$ of smear-negative pulmonary TB cases and $29 \%$ of extrapulmonary TB cases [39]. In the study of SATYANARAYANA et al. [28], $<0.5 \%$ received a regimen without rifampicin and thus received inappropriate treatment. There was no inappropriate treatment regimen prescription in the other studies.

Special groups

Of the 11 studies in special groups, four studies were performed in TB patients with extra-pulmonary TB (table 6) [40-43]. The WHO recommends Category 1 treatment (HRZE or HRZ plus streptomycin (S)) for new cases with severe forms of extra-pulmonary TB and Category 3 treatment for less severe forms (HRZ in 1993 and 1997, HRZE in 2003) [6-8]. In two studies, all patients were treated as recommended by the WHO; these studies had very small sample sizes [41, 42]. In the other two studies, the percentage of inappropriate treatment was $5 \%$ and $18 \%$, respectively $[40,43]$.

One study investigated TB treatment of isoniazid-resistant patients in 2001-2005 [44]. The WHO had no recommendations on appropriate treatment for isoniazid-resistant patients until 2009; therefore, we could not assess the percentage of patients with inappropriate treatment.

Six studies reported on special populations such as pregnant females or AIDS patients. All studies had relatively small sample sizes; between nine and 52 TB patients. Two studies provided sufficient information $(0 \%$ received inappropriate treatment) $[45,46]$, in another two studies $33 \%$ and $67 \%$ received inappropriate treatment, respectively $[47,48]$, and in a further two studies insufficient information was provided $[49,50]$.

\section{DISCUSSION}

In this article we assessed the prevalence of inappropriate prescription of TB drugs (type, dose, frequency of dosing and combination) for treatment of TB. Appropriate treatment was

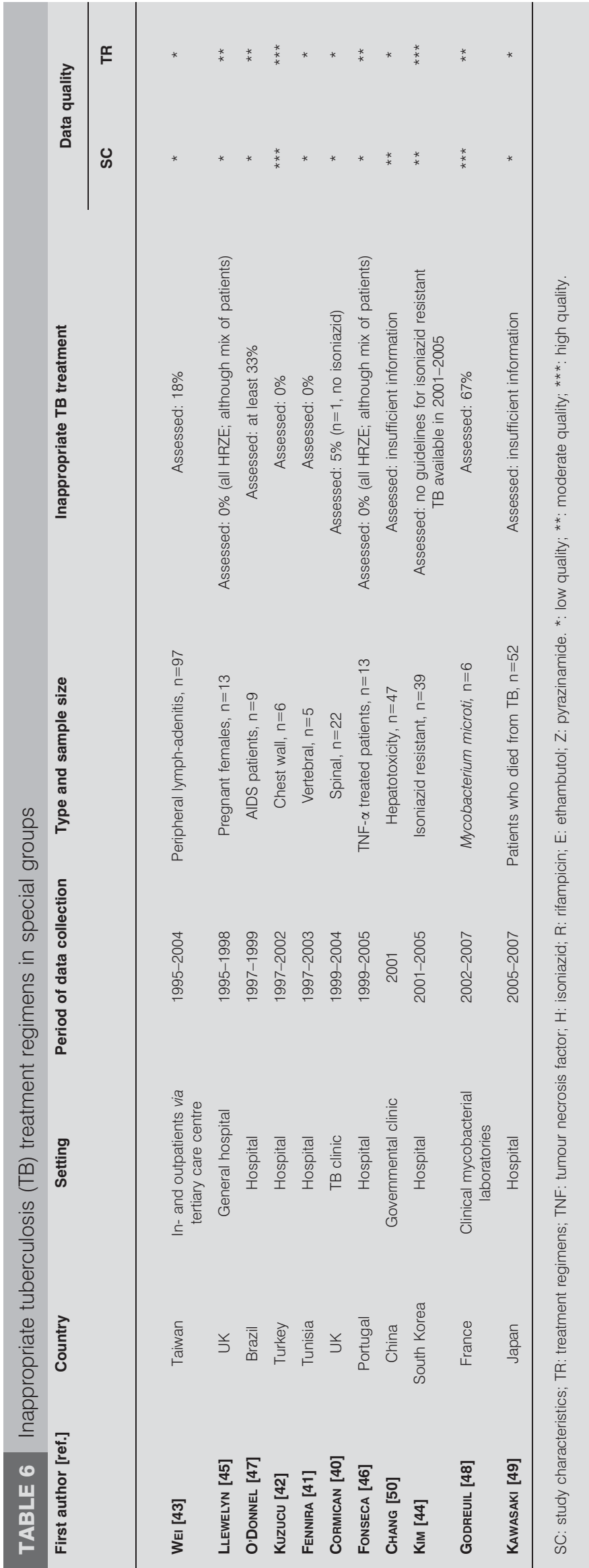


defined according to the WHO guidelines. In total, 37 studies on TB treatment regimens were included. Only eight of these studies (six in the general population and two in special groups) reported all information that was necessary to make an adequate assessment of the prevalence of the inappropriate treatment prescription. The main challenge with the data reporting was that the treatment regimens were often not provided separately for new and re-treatment cases, smearpositive and smear-negative cases, and pulmonary and extrapulmonary TB (e.g. studies stated "all patients started on HRZE"). These patient characteristics are important to consider as the WHO recommends different treatment regimens for each of these categories.

We adopted a broad search and selection strategy to include as many studies as possible with data on prescription of TB treatment regimens. For 13 (35\%) out of the 37 included studies, evaluation of the prescribed treatment was one of the objectives (i.e. being specifically mentioned in the objective or aim of the study) $[15,16,18,24,28,29,31,32,34,35,38,39$, 44]. One would expect that these studies score "moderate" or "high" quality on treatment regimen reporting, but this was only the case for six out of the 12 studies.

In $67 \%$ of the studies, inappropriate treatment regimens were prescribed and the percentage of patients on inappropriate treatment regimens varied widely between $0.4 \%$ and $100 \%$. The data suggest that the prevalence of inappropriate treatment was lower in the more recent years. These findings have to be interpreted with caution, however, as the prevalence could often only be estimated and the quality of reporting was low.

It appears that many of the included studies are from settings that are, or should be, informed on WHO treatment guidelines. Few studies are from private healthcare settings and none of the studies examined patients of individual private doctors. These are two groups of healthcare workers in which familiarity with international TB guidelines might be lower and thus have a higher level of inappropriate treatment prescription. Studies examining what TB treatment regimens private practitioners would prescribe show that often national or international guidelines are not often followed [51-53].

Three studies were based in EU Member States with intermediate-to-low TB incidence (France, Germany and Spain) [36-38] and in all three studies, inappropriate treatment of cases was reported. Although the number of studies is limited and the quality of reporting ranged from low to high, these findings show inappropriate TB treatment is prescribed that in the EU. As stated in the European action plan to fight TB in the EU [54] and the follow-up of the action plan [55], it is essential that all TB patients be diagnosed and provided optimal TB treatment; without such efforts, TB transmission cannot be prevented and TB elimination achieved. Furthermore, the risk for resistance development remains. Regardless of TB incidence in a given setting, providing accurate treatment is essential to prevent transmission as well as prevent development of drug resistance.

In $17(46 \%)$ out of the 37 included studies, the definition of TB diagnosis was not specified. Inspection of the data revealed that the availability of a TB case definition was not related to the quality of reporting of the treatment regimens or prevalence of inappropriate treatment regimens.
$10(27 \%)$ studies had a data collection period that included two or more WHO guideline periods, for example 1993 and 1997. There are differences between the guidelines, the most important being the inclusion of streptomycin in Category 1 treatment. In 1993 and 1997 this was recommended in the guidelines, but not in 2003. In these cases, we considered both HRZE and HRZS as appropriate treatment.

TB treatment consists of different treatment modalities: regimen, dose, frequency and duration. Other important aspects that are necessary for a successful treatment outcome are treatment compliance and quality of the drugs. The WHO guidelines recommend treatment regimens with an intensive and continuation phase (e.g. HRZE for intensive phase and HR for continuation) and with a certain frequency (3 days per week or daily), duration (e.g. 6 months) and dosage (e.g. 4-6 mg. $\mathrm{kg}^{-1}$ INH daily). In this article we could only assess treatment regimen as there was insufficient information on dose, frequency and duration of treatment.

Defining any regimen that is in line with WHO Guidelines as "appropriate" and all others as inappropriate is a rough distinction between right and wrong. Treatment against TB may be inappropriate because: 1) the treatment duration is too short or the regimen contains too few drugs, has insufficient dose or drugs in a wrong combination; or 2) the duration of treatment is too long, with an excessive dose or number of drugs. The first error may cause drug resistance, while the second error increases the risk of side-effects and consequently low-treatment compliance and, thus, increased treatment failure. Unfortunately, in most included studies the treatment regimens were not reported in sufficient detail to make a distinction between these two forms of inappropriate treatment.

\section{Conclusion}

Despite the fact that assessment of the prevalence of inappropriate TB treatment regimens was hampered by low quality of reporting, our data indicate a reasonable amount of inappropriate prescription of TB treatment regimens, as this was observed in the majority of the included studies. Thus, there is a risk that new drugs will be used in inappropriate treatment regimens, even with official WHO guidelines in place, introducing the subsequent risk of resistance development to these new drugs. This article highlights the need to ensure optimal implementation of the WHO treatment of TB guidelines in all settings.

\section{SUPPORT STATEMENT}

This study was financially supported by a European Centre for Disease Prevention and Control direct service contract (publication reference: OJ/2010/07/12-PROC/2010/034).

\section{STATEMENT OF INTEREST}

None declared.

\section{ACKNOWLEDGEMENTS}

We would like to thank R. Spijker (clinical librarian at the Academic Medical Center Amsterdam, Amsterdam, the Netherlands) for assistance with the development of the search strategy and for performing the search. We also would like to thank P. Carillo-Santisteve (European Centre for Disease Control and Prevention, Stockholm, Sweden) for assistance with retrieving the full-text papers. 


\section{REFERENCES}

1 Crofton J, Mitchison DA. Streptomycin resistance in pulmonary tuberculosis. BMJ 1948; 2: 1009-1015.

2 Controlled clinical trial of four short-course (6-month) regimens of chemotherapy for the treatment of pulmonary tuberculosis. Lancet 1974; 2: 1100-1106.

3 World Health Organization. Treatment of tuberculosis guidelines. 4th Edn. Geneva, WHO, 2009.

4 Ma Z, Lienhardt $\mathrm{C}$, McIlleron $\mathrm{H}$, et al. Global tuberculosis development pipeline: the need and the reality. Lancet 2010; 375: 2100-2109.

5 van der Werf MJ, Langendam MW, Huitric E, et al. Multidrugresistance after inappropriate tuberculosis treatement: a metaanalysis. Eur Respir J 2012; [Epub ahead of print DOI: 10.1183/ 09031936.00125711].

6 World Health Organization. Treatment of tuberculosis. Guidelines for national programmes. 1st Edn. Geneva, WHO, 1993.

7 World Health Organization. Treatment of tuberculosis. Guidelines for national programmes. 2nd Edn. Geneva, WHO, 1997.

8 World Health Organization. Treatment of tuberculosis. Guidelines for national programmes. 3rd Edn. Geneva, WHO, 2003.

9 World Health Organization. Global tuberculosis programme. Global tuberculosis control. WHO Report 1997. WHO/TB/ 97.225. Geneva, WHO, 1997.

10 Vandan N, Ali M, Prasad R, et al. Physicians' knowledge regarding the recommended anti-tuberculosis prescribed medication regimen: a cross-sectional survey from Lucknow, India. Southeast Asian J Trop Med Public Health 2008; 39: 1072-1075.

11 Udwadia ZF, Pinto LM, Uplekar MW. Tuberculosis management by private practitioners in Mumbai, India: has anything changed in two decades? PLoS One 2010; 5: e12023.

12 Shimeles E, Aseffa A, Yamuah L, et al. Knowledge and practice of private practitioners in TB control in Addis Ababa. Int J Tuberc Lung Dis 2006; 10: 1172-1177.

13 European Centre for Disease Prevention and Control, World Health Organization Regional Office for Europe. Tuberculosis Surveillance in Europe 2009. Stockholm, European Centre for Disease Prevention and Control, 2011.

14 Ishikawa N, Ahiko T. [Breakthrough for tuberculosis control program in Japan]. Kekkaku 2003; 78: 107-110.

15 Maseeh A, Dadhich AP, Agarwal AK. Drug prescribing pattern in patients admitted with tuberculosis in a tertiary care hospital. Asia Pacific J Pharmacol 2004; 4: 16-18.

16 Thongraung W, Chongsuvivatwong V, Pungrassamee P. Multilevel factors affecting tuberculosis diagnosis and initial treatment. J Eval Clin Pract 2008; 14: 378-384.

17 Diop AH, Gakiria G, Pande SB, et al. Dosages of anti-tuberculosis medications in the national tuberculosis programs of Kenya, Nepal, and Senegal. Int J Tuberc Lung Dis 2002; 6: 215-221.

18 Khan JA, Hussain SF. Anti-tuberculous drug prescribing: doctors' compliance at a private teaching hospital in Pakistan. Trop Doct 2003; 33: 94-96.

19 Quy HT, Cobelens FGJ, Lan NTN, et al. Treatment outcomes by drug resistance and HIV status among tuberculosis patients in Ho Chi Minh City, Vietnam. Int J Tuberc Lung Dis 2006; 10: 45-51.

20 Ohkado A, Aguiman L, Adlawan S, et al. Tuberculosis drug resistance and treatment outcomes under DOTS settings in large cities in the Philippines. Int J Tuberc Lung Dis 2006; 10: 283-289.

21 Koh W-J, Kwon OJ, Kim CH, et al. Clinical characteristics and treatment outcomes of patients with pulmonary tuberculosis at a private general hospital. Tuberc Res Dis 2003; 55: 154-164.

22 Chamla DD, Nie S, Duan Q. Retrospective descriptive study of adult tuberculosis in Wuhan, China. Int J Tuberc Lung Dis 2004; 8: 730-736

23 Quy HT, Lonnroth K, Lan NT, et al. Treatment results among tuberculosis patients treated by private lung specialists involved in a public-private mix project in Vietnam. Int J Tuberc Lung Dis 2003; 7: 1139-1146.

24 Chiang C-Y, Bai K-J, Lee C-N, et al. Inconsistent dosing of antituberculosis drugs in Taipei, Taiwan. Int J Tuberc Lung Dis 2010; 14: 878-883.

25 Datta BS, Hassan G, Kadri SM, et al. Multidrug-resistant and extensively drug resistant tuberculosis in Kashmir, India. J Infect Dev Ctries 2010; 4: 19-23.

26 Chengsorn N, Bloss E, Anekvorapong R, et al. Tuberculosis services and treatment outcomes in private and public health care facilities in Thailand, 2004-2006. Int J Tuberc Lung Dis 2009; 13: 888-894.

27 Liu Q, Smith H, Wang Y, et al. Tuberculosis patient expenditure on drugs and tests in subsidised, public services in China: a descriptive study. Trop Med Int Health 2010; 15: 26-32.

28 Satyanarayana S, Shivashankar R, Vashist RP, et al. Characteristics and programme-defined treatment outcomes among childhood tuberculosis (TB) patients under the national TB programme in Delhi. PLoS One 2010; 5: e13338.

29 Tuberculosis Surveillance Center, RIT, JATA. [Tuberculosis annual report 2008 - Series 8. Treatment of TB (1)]. Kekkaku 2010; 85: 561-564.

30 Van Zyl S, Marais BJ, Hesseling AC, et al. Adherence to antituberculosis chemoprophylaxis and treatment in children. Int $J$ Tuberc Lung Dis 2006; 10: 13-18.

31 Salaniponi FM, Nyirenda TE, Kemp JR, et al. Characteristics, management and outcome of patients with recurrent tuberculosis under routine programme conditions in Malawi. Int J Tuberc Lung Dis 2003; 7: 948-952.

32 Harries AD, Gausi F, Salaniponi FM. Prescriptions and dosages of anti-tuberculosis drugs in the National Tuberculosis Control Programme of Malawi. Int J Tuberc Lung Dis 2004; 8: 724-729.

33 Elmahalli AA, Abdel-Aziz BF. Assessment of the implementation of DOTS strategy in two chest facilities in Alexandria, Egypt. East Mediterr Health J 2007; 13: 1085-1097.

34 Lalya F, Ocheke IE, Hounnou-d'Almeida M, et al. Paediatric tuberculosis at the national teaching hospital CNHU-HKM of Cotonou, Benin: a retrospective study. West Afr J Med 2010; 29: 263-266.

35 Richardson NL. Evaluating provider prescribing practices for the treatment of tuberculosis in Virginia, 1995 to 1998: an assessment of educational need. J Contin Educ Health Prof 2000; 20: 146-155.

36 Grupo de Trabajo del PMIT. Diagnostico y tratamiento de la tuberculosis en Espana: resultados del Proyecto Multicentrico de Investigacion en Tuberculosis (PMIT) [Diagnosis and treatment of tuberculosis in Spain: results of the Multicenter Project for Tuberculosis Research]. Med Clin (Barc) 2001; 116: 167-173.

37 Diel R, Niemann S. Outcome of tuberculosis treatment in Hamburg: a survey, 1997-2001. Int J Tuberc Lung Dis 2003; 7: 124-131.

38 Valin N, Hejblum G, Borget I, et al. Factors associated with excessively lengthy treatment of tuberculosis in the eastern Paris region of France in 2004. BMC Public Health 2010; 10: 495.

39 Hasker E, Khodjikhanov M, Usarova S, et al. Drug prescribing practices for tuberculosis in Uzbekistan. Int J Tuberc Lung Dis 2009; 13: 1405-1410.

40 Cormican L, Hammal R, Messenger J, et al. Current difficulties in the diagnosis and management of spinal tuberculosis. Postgrad Med J 2006; 82: 46-51.

41 Fennira H, Bourguiba M, Ben RN, et al. Vertebral tuberculosis revealed by thoracic manifestations. A study of five cases. Tunis Med 2006; 84: 811-815.

42 Kuzucu A, Soysal O, Gunen H. The role of surgery in chest wall tuberculosis. Interact Cardiovasc Thorac Surg 2004; 3: 99-103.

43 Wei YF, Liaw YS, Ku SC, et al. Clinical features and predictors of a complicated treatment course in peripheral tuberculous lymphadenitis. J Formos Med Assoc 2008; 107: 225-231. 
44 Kim YH, Suh GY, Chung MP, et al. Treatment of isoniazidresistant pulmonary tuberculosis. BMC Infect Dis 2008; 8: 6.

45 Llewelyn M, Cropley I, Wilkinson RJ, et al. Tuberculosis diagnosed during pregnancy: a prospective study from London. Thorax 2000; 55: 129-132.

46 Fonseca JE, Canhao H, Silva C, et al. Tubereulose em doentes reumaticos tratados com antagonistas do factor de necrose tumoral alfa: a experiencia Portuguesa [Tuberculosis in rheumatic patients treated with tumour necrosis factor alpha antagonists: the Portuguese experience]. Acta Reumatol Port 2006; 31: 247-253.

47 O'Donnel MM, Souza CS, Gadelha AJ, et al. Poor response to tuberculosis treatment with regimens without rifampicin in immunosuppressed AIDS patients. Braz J Infect Dis 2002; 6: 272-275.

48 Godreuil S. Human pulmonary tuberculosis due to Mycobacterium microti: description of 6 recent cases in France. Clin Microbiol Infect 2009; 15: Suppl. s4, s131.

49 Kawasaki T, Sasaki Y, Nishimura H, et al. [A hospital based study on evaluation of causes of death in 52 patients with pulmonary tuberculosis]. Kekkaku 2009; 84: 667-673.
50 Chang KC, Leung CC, Yew WW, et al. Hepatotoxicity of pyrazinamide: cohort and case-control analyses. Am J Respir Crit Care Med 2008; 177: 1391-1396.

51 Auer C, Lagahid JY, Tanner M, et al. Diagnosis and management of tuberculosis by private practitioners in Manila, Philippines. Health Policy 2006; 77: 172-181.

52 Ayaya SO, Sitienei J, Odero W, et al. Knowledge, attitudes, and practices of private medical practitioners on tuberculosis among HIV / AIDS patients in Eldoret, Kenya. East Afr Med J 2003; 80: 83-90.

53 Shah SK, Sadiq H, Khalil M, et al. Do private doctors follow national guidelines for managing pulmonary tuberculosis in Pakistan? East Mediterr Health J 2003; 9: 776-788.

54 European Centre for Disease Prevention and Control. Framework Action Plan to Fight Tuberculosis in the Europe Union. Stockholm, European Centre for Disease Prevention and Control, 2008.

55 European Centre for Disease Prevention and Control. Special Report: Progression towards TB elimination. A follow-up to the Framework Action Plan to Fight Tuberculosis in the Europe Union. Stockholm, European Centre for Disease Prevention and Control, 2010. 